\title{
Reviewers for Indian Journal of Medical and Paediatric Oncology
}

\author{
Padmaj Kulkarni ${ }^{1}$ \\ ${ }^{1}$ Deenanath Mangeshkar Hospital and Research Center, Erandwane, \\ Pune, Maharashtra, India \\ Ind J Med Paediatr Oncol 2022;43:129-130.
}

\begin{abstract}
Address for correspondence Padmaj Kulkarni, MD, DM, Deenanath Mangeshkar Hospital and Research Center, Deenanath Mangeshkar Hospital Road, Near Mhatre Bridge, Erandwane, Pune, Maharashtra 411004, India (e-mail: editorijmpo@gmail.com).
\end{abstract}

IJMPO family is indebted to our peer reviewers. Structuring a good review is time-consuming and effort-intensive. We deeply value the inputs of all the reviewers who volunteer their time and expertise to provide essential feedback and suggestions to the authors as well as the editorial board and ensure the quality of research published in IJMPO. We would like to thank the

following reviewers for contributing to this issue:

Abhishek Shrivastava
Arjun Gupta
Arun Goel
Barnini Ghosh
Bharadwaj Ponnada
Chakor Vora
Deepa Joy Phillip
Gaurav Prakash
Geethanjali Amin
Hemanth Kumar
Imran Khan
Jyoti Bajpai
Kanhu Patro
Megha Saroha
Moses Arunsingh
Nikhil Kalyani
Nitish Garg
Perumal Kalaiyarasi Jayachandran
Prateek Kinra
Raghunadharao Digumarti
Rajashree Ashwath
Rohan Tewani

Abhishek Shrivastava

DOI https://doi.org/ $10.1055 / \mathrm{s}-0042-1744357$ ISSN 0971-5851.

\author{
Rohit Reddy \\ Sabeena Choudhary \\ Sachin Khurana \\ Sandeep Bairwa \\ Sayan Das \\ Senthil Rajappa \\ Shina Goyal \\ Shivashankara MS \\ Shona Nag \\ Shuvadeep Ganguly \\ Siva Prasad \\ Sneha Bothra Jain \\ Sreevalli A. \\ Srujuna Joga \\ Stalin Chowdary Bala \\ Sujith Kumar Mullapally \\ Sumit Mukhopadhyay \\ Thejeswar Nakka \\ TVSVGK Tilak \\ Usha Rani Poli \\ Yogesh Kulkarni
}

(c) 2022. Indian Society of Medical and Paediatric Oncology. All rights reserved.

This is an open access article published by Thieme under the terms of the Creative Commons Attribution-NonDerivative-NonCommercial-License, permitting copying and reproduction so long as the original work is given appropriate credit. Contents may not be used for commercial purposes, or adapted, remixed, transformed or built upon. (https://creativecommons.org/ licenses/by-nc-nd/4.0/)

Thieme Medical and Scientific Publishers Pvt. Ltd., A-12, 2nd Floor, Sector 2, Noida-201301 UP, India 